\title{
Sizing the Components of Existing Machinery to Gradually Develop Machine Design Expertise
}

\section{Dr. Juan C. Morales P.E., Universidad del Turabo}

Dr. Juan C. Morales, P.E. After seven years in private industry, Dr. Morales joined the Mechanical Engineering Department at Universidad Ana G. Mendez - Gurabo Campus (formerly Universidad del Turabo) in 1995 and currently holds the rank of professor. Dr. Morales was the ABET Coordinator of the School of Engineering for the initial ABET-EAC accreditation of all five accredited programs at UT. He has been Department Head of Mechanical Engineering since 2003. He has dedicated his efforts to diffuse innovative teaching and learning practices in the school. These efforts derive directly from the outcomes assessment plan which he helped devise and implement as ABET Coordinator.

Address: Department of Mechanical Engineering, Universidad Ana G Mendez - Gurabo Campus, PO Box 3030, Gurabo, Puerto Rico, 00778.

Tel. 787-743-7979 x 4182

E-mail: jcmorales@suagm.edu 


\title{
Sizing the components of existing machinery to gradually develop machine design expertise
}

\author{
Juan C. Morales, Ph.D., P.E. \\ Universidad Ana G. Méndez - Gurabo Campus \\ (formerly Universidad del Turabo)
}

\begin{abstract}
Typical design (sizing) projects in a Machine Design course tend to rely on abstractions of the machine; that is, situations in which the student must imagine the system, perhaps with the aid of a 2D schematic, and conduct the sizing calculations in a completely theoretical and abstract fashion. This skill is certainly a requirement of an experienced machine designer; however, novices may be outmatched when exposed to this level of expertise at an early stage in their development. This article suggests that the sizing projects should be based on existing machinery that is available in the university, and that is accessible for inspection and exploration by students. The sizing results are then compared to the existing machine to determine the reasonableness of the calculations. This approach "conditionalizes" knowledge and provides students with an intermediate design experience before undertaking a major machine design experience in their capstone course. Furthermore, based on the "backwards design" planning framework for designing courses, the paper suggests that the project should be approached gradually - in phases - from the first day of class, and extending throughout the semester, to provide quality feedback to students throughout the entire process, thus increasing the potential of achieving expertise. The phases were also synchronized with the material presented in class, and with the exams, to further strengthen the knowledge acquired by the students. The project specifically addressed the sizing of components of an existing SAE Baja race car gearbox (size the shafts, keys, gears, and bearings). Phases 1 and 2 of the project asked students to calculate/estimate the external loads acting on the input and output shafts of the gearbox. In these first two phases students were able to start experiencing a typical real-world situation in which, unlike textbook problems, the loads acting on the system were unknown and had to be determined. It required searching the internet, consulting textbooks, inspecting the Baja, and making assumptions. In the last phases, the students compared the results of their sizing calculations to the existing components and applied critical thinking skills (discern the true from the false and be able to explain it) to explain differences in the sizes of the components. This study is based on the literature on expertise, and the learning processes that support its development. A survey of skills, given as a pre- and post-survey to students, validates the strength of using this scheme. The survey results were further validated by direct assessment of the written reports.
\end{abstract}




\section{Introduction}

Typical design projects in a junior-level Machine Design course tend to rely on abstractions; that is, situations in which the students must imagine the machine that they will design, perhaps with the aid of a 2D schematic provided by the instructor, and conduct the sizing calculations in a completely theoretical and abstract fashion. This skill is certainly a requirement of an experienced machine designer; however, novices may be outmatched when exposed to this level of expertise at an early stage in their development.

Sizing may be defined as the process of scientifically calculating the dimensions of parts such that they will not fail when subjected to a specified loading condition. The process of "sizing" is very similar to "analysis" - after all, they use the same equations - except that in sizing, the unknown variable is always a part dimension; for example, the diameter of a shaft, the length of a fillet weld, or the diametral pitch (tooth size) of a gear.

The objective of this investigation was to determine the effectiveness of using an existing machine - a tangible, real -world system that contextualizes the learning process, and which students could freely inspect and explore - as the basis for the sizing project. The author hypothesized that this exercise could develop students' expertise and engineering judgment, in addition to strengthening the knowledge of statics and mechanics of materials which are crucial prerequisite skills. The development of engineering judgment would occur through the application of critical thinking skills; i.e., the capacity to discern the true from the false and to be able to explain it. The pedagogical construct of "comparison" would be used to compel the critical thinking process to take place. Are the students' sizing results comparable to the existing part dimensions of the machine? Can they explain the differences in their sizing results, if any, when compared to the existing piece of machinery? What can they say about the safety factors that the original designers probably used? The pedagogical benefits of this approach are further explained in the literature review section of the article.

The author was motivated by weaknesses that he had observed in senior students' mastery of the fundamental concepts of statics, mechanics of materials, and sizing of machine components. These weaknesses are not isolated to this particular university; for example, the authors of the textbook used in the course, Juvinall and Marshek [1], point out in the preface that "most teachers of Mechanical Engineering Design lament the weakness of their students in the area of free-body diagram analysis of loads. Unless the loading on a machine component is properly established, subsequent design or analysis is of little value".

The author was also motivated by observing overmatched students in machine design projects that were based on abstractions and, furthermore, also required the comprehensive systemsengineering approach that is used in the capstone course. The author observed that the additional capstone-like requirements diluted the emphasis on developing expertise in sizing. Students also struggled to satisfy all the additional project requirements in a timely manner. The approach suggested in this article would represent an intermediate sizing experience, where the fundamentals of machine component sizing would be solidly mastered, before undertaking the major design experience in the capstone course. This sequence is represented in Fig. 1. 


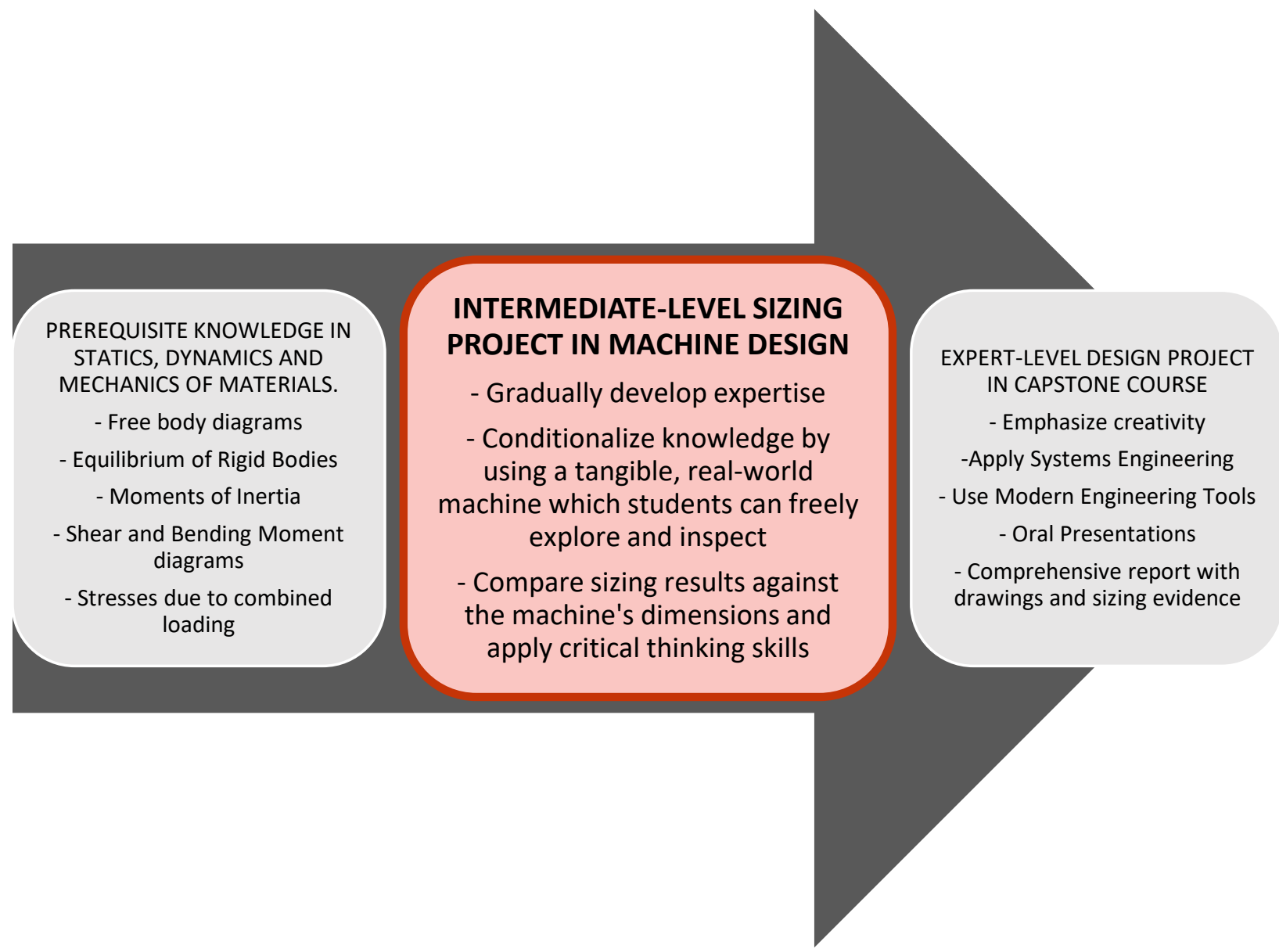

Fig. 1. Proposed sequential scheme to gradually develop expertise in machine design. Emphasis is placed on the second stage, which is the theme of this article.

To ensure that the project had a proper fit within the course, the author used the "backwards design" planning framework promoted by Wiggins and McTighe [2] to make it more likely that, by design, students would be able to achieve the goals of the course. "Backwards design" has three steps: 1.) Determine the desired results/goals, 2.) Determine what would be acceptable evidence of accomplishing the results/goals and, 3.) Plan appropriate learning experiences and instruction methods. This exercise is challenging and thought-provoking. It forces the educational designer to look at an entire course, in both the short-term and the long-term, and prioritize. While prioritizing, it forces the instructor to limit the number of topics, objectives, and activities in the course. Instructors have only two or three sessions (1.5 hours each), on average, to dedicate to each machine element and other activities. The results of the planning framework exercise are presented in Fig. 2. 


\section{Identify desired results/goals}

a)Students shall master the art and science of sizing machine components aided only by a calculator, which is the only device allowed in the PE licensure exam. The word "art" is defined here as the application of engineering judgment to synthesize the entire machine after scientifically calculating the sizes for each individual machine component.

\section{Determine acceptable evidence of accomplishing the desired results}

a)Students shall be able to show evidence of mastery of sizing machine elements in both, traditional exams, and in a real-world sizing project of a subsystem comprised of typical machine elements.

\section{Learning experiences and instruction}

a)Focus the entire course on sizing, from day one. Review prerequisite material on statics and mechanics of materials in a just-in-time manner, when required, and in context. In context means that the review will be directly related to a machine component that is being addressed in class.

b)Announce the project on day one and divide it into phases so that formative feedback can be provided to students throughout the entire semester.

c)Synchronize the presentation of class material with the real-world sizing project and with the exams so that they strengthen each other, i.e., studying for the exam will assist them with the project phase, or vice versa.

d)The material presented in class shall provide enough knowledge to solve most of the sizing project requirements.

e)Intentionally leave some knowledge gaps for students to explore on their own when they are working on the project (tight and slack tensions on belt drives, for example). This requirement develops the skill of finding information on their own and directly addresses ABET outcome 7 [3].

f)There must be a way for students to tangibly check the validity of their sizing calculations so that they can develop critical thinking, engineering judgment and expertise. This requirement will be met by using a tangible, real-world existing machine as the basis for the sizing project. Students will compare their results to the dimensions of the existing machine.

g)Students shall be exposed to selecting components from manufacturers' catalogues.

h)The project shall be constrained to be of zero cost, must be completed in one semester, and must not involve any curricular changes such as adding a laboratory or extra hours.

Fig. 2. Results of the "backwards design" planning framework promoted by Wiggins and McTighe [2] to fit the project within the entire scope of the machine design course.

The machine subsystem addressed in this article was the speed reducer gearbox of a SAE Baja off-road race car that competed in 2012 race (Auburn) sponsored by the Society of Automotive Engineers (SAE). The speed reducer is shown in Fig. 3. The students were able to inspect the SAE Baja used in the 2016 competition (Fig. 4). Students were required to size all the shafts, keys, gears, and bearings of the gearbox. The input shaft and gear are not shown because they failed during the 2012 competition and were lost. One of the reasons for selecting the SAE Baja was to promote the competition which has been very fruitful at this university, but which has recently lost some impetus in the department. 

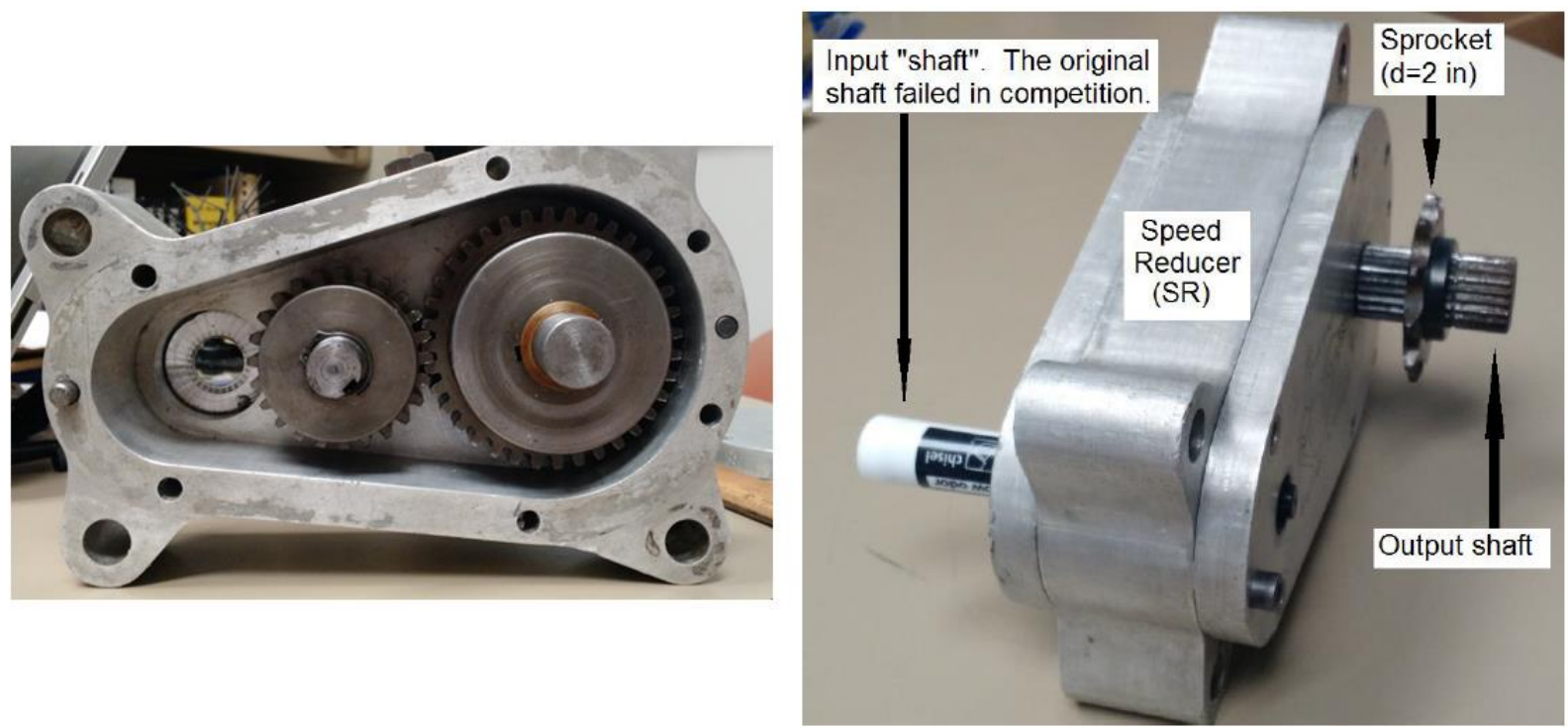

Fig. 3. Gearbox of the SAE Baja that competed in the 2012 (Auburn) competition.
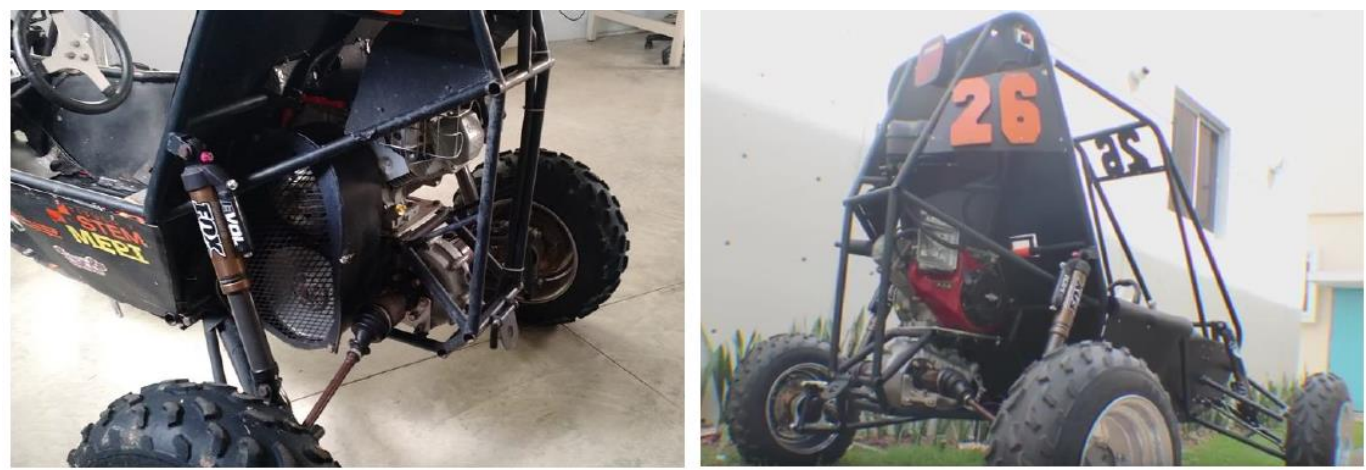

Fig. 4. 2016 SAE Baja that was also available for inspection.

\section{Literature Survey}

Bransford, et al. [4] indicate that the transfer of knowledge from school to the context of practical work experiences is one of the most important outcomes of formal schooling. Bornasal, et al., [5] citing from several authors, mention that the process of knowledge transfer has been linked to the following five items: 1.) expertise, 2.) active engagement and deliberate practice, 3.) motivation, 4.) context of learning, and 5.) self-explanation. Regarding expertise, Litzinger, et al. [6] indicate that, while experts evidently have more knowledge in their domain than novices, an even more important characteristic is that the knowledge of experts is organized based on a deep understanding of their domain and organized around key concepts. In terms of a machine design course, these key concepts include Newton's three laws of motion and the proper use of free body diagrams, the stress at a point in a machine element due to combined loading, 
and failure theories, among others. Bransford, et al. indicate that if the knowledge is well organized, it is apt to transfer, and when knowledge is poorly organized or disconnected, such as knowledge obtained by rote learning, it is unlikely to transfer. They also indicate that experts organize their knowledge such that it includes "specifications of the context in which it is useful" and can therefore be easily recalled." When linked to useful contexts, knowledge is referred to as being "conditionalized". Bransford, et al. emphasize "the need to create learning environments that explicitly lead students to develop conditionalized knowledge rather than leaving it to students to learn the conditions under which knowledge and skills can be applied". They also mention that the process of learning requires the three fundamental components of guidance, practice and feedback.

Citing from Entwistle, et al. [7], Litzinger, et al. mention the following strategies to promote deep learning: 1.) relating ideas to previous knowledge and experience, 2.) looking for patterns and underlying principles, 3.) checking evidence and relating it to conclusions, and 4.) examining logic and argument cautiously and critically.

Citing from Vermunt [8], Litzinger, et al. identified additional deep approaches for what Vermunt called "application oriented students": 1.) searching for relations between the subject matter and the reality to which it refers, 2.) trying to apply in practice what has been learned in a course, and 3.) seeking to fill abstract lines of reasoning with concrete things.

The approach described in this article satisfies many of these literature findings; most importantly, the existing machine creates a learning environment that explicitly leads students to develop "conditionalized knowledge" [4]. In addition, it "fills abstract lines of reasoning with concrete things" [8], assists in "organizing knowledge around key concepts" [6] so that it is more apt to transfer, and it induces students to "search for relations between the subject matter and the reality to which it refers" [8]. When students conduct the sizing calculations they are "relating ideas to previous knowledge and experience" [7] of the statics and mechanics of materials prerequisites while always referring it to the tangible, real-world existing machine. The exams and the projects are directly related to the course material so that the student "applies into practice what has been learned in the course" [8]. The process of comparing the sizing results to the dimensions of the existing machine provides a path for "checking evidence and relating it to conclusions" [8], as well as for "examining logic and argument cautiously and critically". By conducting the project in phases throughout the semester, it applies the "guidance, practice, and feedback" [4] requirement for effective learning experiences.

While searching the literature, the author could not find a similar scheme that focused its approach on achieving sizing expertise by "conditionalizing" the learning experience with an existing machine. However, there were other noteworthy approaches which are summarized below.

Pierce, et al. [9] presented a comprehensive design experience that consisted of designing several components of a ski lift system. The machine design course included a laboratory, which is not typical in mechanical engineering curricula, but was very effective in providing the additional time to conduct a thorough learning experience with multiple requirements. The lab was well 
coordinated with the course and emphasized modern engineering analysis tools such as finite element analysis. It was not evident if students compared their results to similar ski lifts to critically evaluate the reasonableness of their sizing calculations.

Youssef, et al. [10] redesigned the machine design course to include a comprehensive design experience that satisfied most of the steps of a capstone project. It also included a patent search. This scheme is similar to Pierce, et al. [9] in its comprehensiveness and the multitude of project requirements; however, it lacked a laboratory period that would have provided additional time to fulfil the additional requirements. The clear trade-off in this scheme is that the effort to achieve mastery in sizing machine components is diluted due to the several requirements of the capstonelike project that consume a significant amount of students' time. It was not evident if students had a way of determining the reasonableness of their results.

Wood, et al [11] promoted tinkering through a hands-on environment with breadboards. They provided several alternatives of "breadboards", some of which required electromechanical knowledge. The emphasized breadboard consisted of a radio controlled (RC) toy car that had a variety of parts of different sizes that could be interchanged. By experimenting with the different parts, students were able to test real-life results of the changes through sensitivity studies, which develops engineering judgment and critical thinking. There was high student satisfaction with the hands-on experience. Each RC car had a cost that ranged between $\$ 150$ - $\$ 1,000$. The project was not capstone-like, so the students' efforts were not diluted with the additional requirements. In a separate article [12], the author describes a multi-media-based review of mechanics of materials that was implemented in the course as a result of cutting $25 \%$ of the course content to include the hands-on experience. The responsibility for reviewing the material was placed on the students, i.e., students had to conduct the review on their own time, outside of class.

Farouki, et al. [13] also promoted tinkering through a hands-on environment by having students design and fabricate a Shigley Hauler toy machine which was then used in a school competition. The Shigley Hauler consists of a mechanical system with limited power and transmission resources that is used to raise a load (as many Shigley textbooks as possible, hence its name) up an inclined plane. Students were provided with a small DC motor and a set of 10 plastic gears. Farouki, et al. reported a high level of student satisfaction, increased enrolment, and student enthusiasm because of this competitive experience, which they have held for more than 10 years at UC Davis. The clear trade-off in this experience is the limited emphasis on developing the skill of sizing machine components. Students only sized the shafts. Shaft sizing, however, was constrained by the fact that the inner hub diameter of the plastic gears could not be increased (without weakening the gear) to fit a larger calculated diameter shaft size. Also, the students' emphasis on fabrication (not sizing) had to be curtailed, as evidenced by a project guideline which included the following warning to students: "Do not rush into building your device!, the instructor needs to see evidence that your success (or lack thereof) results from engineering insight, rather than just dumb luck or brutish trial-and-error!" [14]. Due to the limited sizing opportunities, this hands-on activity seems to have a better fit in a dynamics class with the 
emphasis placed on "conditionalizing" the concepts of gear ratios, mechanical advantage, and the kinetics involved during the raising of the load.

Yilmaz [15] conducted a wheel balancing machine design project in a Mechanical Technology program. The project included fabrication of the system and required several semesters with different students working on the same project. The author reported that, due to some mechanical and instrumentation related technical difficulties, "this fairly complicated class project turned out to be an applied research project". Even though it is for a technology program, which has different goals than a BS in mechanical engineering program, this article clearly presents the pitfall of having a project whose scope is overly ambitious.

It would be ideal if all the excellent ideas presented in this section could be included in a machine design course, that is, hands-on experiences that promote tinkering; fabrication and sensitivity studies; the use of modern engineering tools such as finite element analyses; and the comprehensive systems-engineering approach of the capstone course. However, it all comes down to priorities, as indicated by Wiggins and McTighe [2]. It is evident that instructors have a variety of visions of how to conduct a machine design course, each with its own merits and sacrifices.

\section{Methods}

The project specifically addressed the sizing of shafts, keys, gears, and bearings of an existing SAE Baja race car gearbox (Figs. 3 and 4). It was divided into the six phases shown in Fig. 5, which were equally weighed in the grade:

The survey shown in Fig. 6 was distributed as a pre-survey at the beginning of the semester and as a post-survey at the end of the semester to assess the results. The survey contains a set of nine skills. Skills S1-S3 refer to issues confronted in the real-world, S4-S6 refer to prerequisite materials on statics and strength of materials, and S7-S9 refer to skills developed in the machine design course, particularly S9 (failure theories). While S7 (identifying critical points) and S8 (stress state due to combined loading) are covered in mechanics of materials, it is in the machine design course that students truly develop expertise using these skills.

The results of the survey were compared to direct assessment conducted by the author while grading each of the phases.

Comments by students were also used to assess the study. 


\section{Phase 1}

- Calculate the external loads acting on the input shaft of the gearbox. The maximum gear ratio of the CVT $(3.83: 1)$ was provided as data. The students were required to inspect the engine and consult the internet to determine maximum horsepower, torque and rpm. They were required to learn on their own the force distribution on the tight and slack side of a belt drive and apply that knowledge to the CVT to determine the maximum overhung load on the input shaft of the speed reducer. In this first phase, students were able to start experiencing a typical real-world situation in which, unlike textbook problems, the loads acting on the system were unknown and had to be determined. It required searching the internet, consulting textbooks, inspecting the Baja, making assumptions, and performing calculations.

\section{Phase 2}

- Calculate the external loads acting on the output shaft of the gearbox. The gearbox output shaft used a 2-inch sprocket and a chain to drive the rear live axle of the Baja which used a 7-inch diameter sprocket.

\section{Phase 3}

-Determine the gear forces and reactions at the ball bearings for the existing gearbox. This phase provided practice on using three-dimensional free-body diagrams and prepared them for the next phase.

\section{Phase 4}

- Calculate gear sizes and select them from the Boston Gear catalogue. Assume a service factor for the gears and defend your selection.

\section{Phase 5}

-Draw in SolidWorks $\circledast$ the selected gears, calculate the bearing reactions, and compare the selected gear sizes to the original gearbox.

\section{Phase 6}

- Calculate the size of ball bearings, and calculate the shaft diameters based on three failure criteria: bending fatigue, static torsion, and deflection. Use the largest of the three calculated shaft diameters to calculate the critical speed of the shafts to ensure that it is at least $2 x$ higher than the maximum operating speed of the shaft. Reconcile the different sizes of the bearings, gears and shafts and make your final selection of the bearings from the Timken Bearings catalogue.

Fig. 5. The six phases of the project. 


\section{MEEN 425 Design of Machine Elements Survey - Fall 2018}

This survey is anonymous. The aggregate of your responses will be calculated and used to understand your background and to improve the course. Please answer sincerely. Do not be afraid to "Strongly Disagree" (score of " 1 ", see table below), if that is the case.

Likert scale used in the Survey (refer to the five columns on the right of the table)

\begin{tabular}{|c|c|c|c|c|}
\hline 1 & 2 & 3 & 4 & 5 \\
Strongly Disagree & Disagree & Neutral & Agree & Strongly Agree \\
\hline
\end{tabular}

Answer the following statement with an " $\mathrm{X}$ " in one of the five columns on the right of the table:

I feel confident about my abilities in the following skills (see table below) in the context of applying them on a real world machine such as the speed reducer gearbox of the SAE Minibaja.

\begin{tabular}{|c|c|c|c|c|c|c|}
\hline & & & ert- & cale & $\mathrm{scC}$ & \\
\hline & Skill. Each skill starts with "I feel confident about my abilities in..." & 1 & 2 & 3 & 4 & 5 \\
\hline Q1 & $\begin{array}{l}\text { Skill 1: Figuring out the magnitudes and directions of external loads acting } \\
\text { on the system. Textbook problems usually give the external loads but in real } \\
\text { world problems, you must use your ingenuity to determine them. }\end{array}$ & & & & & \\
\hline Q2 & $\begin{array}{l}\text { Skill 2: Finding out information on your own. This may be accomplished by } \\
\text { reading books or searching the internet or other related form of self- } \\
\text { learning. }\end{array}$ & & & & & \\
\hline Q3 & $\begin{array}{l}\text { Skill 3: Working hands-on with machinery, including measuring it, or } \\
\text { assembling it, or repairing it. }\end{array}$ & & & & & \\
\hline Q4 & $\begin{array}{l}\text { Skill 4: Drawing free-body diagrams and setting up the equations of } \\
\text { equilibrium of the system. }\end{array}$ & & & & & \\
\hline Q5 & Skill 5: Drawing a shear force and bending moment diagram of a beam. & & & & & \\
\hline Q6 & $\begin{array}{l}\text { Skill 6: Calculating normal and shear stresses, given the forces and moments } \\
\text { in the system (see skills } 4 \text { and } 5 \text { above). }\end{array}$ & & & & & \\
\hline Q7 & $\begin{array}{l}\text { Skill 7: Identifying the critical points (points of highest stress) in a beam in } \\
\text { bending, a circular bar in torsion, any bar under uniaxial load, and a bolt in } \\
\text { single shear. }\end{array}$ & & & & & \\
\hline Q8 & $\begin{array}{l}\text { Skill 8: Setting up a combined-loading stress state at a } \\
\text { critical point, i.e., identifying and formulating the } \\
\text { expressions for } \sigma_{x}, \sigma_{y} \text {, and } \tau_{x y} \text { in the figure shown on } \\
\text { the right, based on the forces and moments calculated } \\
\text { with the use of free-body diagrams. }\end{array}$ & & & & & \\
\hline Q9 & Skill 9: Using an appropriate failure theory to size a machine component. & & & & & \\
\hline
\end{tabular}

Fig. 6. Survey used in the study. It was conducted at the beginning (pre) and at the end (post) of the Fall 2018 semester. 


\section{Results}

The results of the pre- and post-surveys are shown in Table 1. The results improved from pre- to post- in all nine skills. Furthermore, the difference in the averages was shown to be statistically significant $(\mathrm{p}$-value $<0.01)$ in all nine skills.

Table 1. Pre and Post Survey Results. The increase in the averages from pre- to post- were statistically significant (p-value $<0.01$ ).

\begin{tabular}{llcc}
\hline S\# & Skill. Each skill starts with "I feel confident about my abilities in..." & $\begin{array}{c}\text { Pre } \\
\text { Avg. }\end{array}$ & $\begin{array}{c}\text { Post } \\
\text { Avg. }\end{array}$ \\
\hline S1 & $\begin{array}{l}\text { Skill 1: Figuring out the magnitudes and directions of external loads acting } \\
\text { on the system. Textbook problems usually give the external loads but in } \\
\text { real world problems, you must use your ingenuity to determine them. }\end{array}$ & 3.1 & 4.3 \\
& &
\end{tabular}

S2 Skill 2: Finding out information on your own. This may be accomplished $\quad 3.5 \quad 4.5$ by reading books or searching the internet or other related form of selflearning.

S3 Skill 3: Working hands-on with machinery, including measuring it, or $\quad 3.8 \quad 4.4$ assembling it, or repairing it.

S4 Skill 4: Drawing free-body diagrams and setting up the equations of $\quad 3.4 \quad 4.3$ equilibrium of the system.

S5 Skill 5: Drawing a shear force and bending moment diagram of a beam. $\quad 3.1 \quad 4.4$

S6 Skill 6: Calculating normal and shear stresses, given the forces and $\quad 3.6 \quad 4.4$ moments in the system (see skills 2 and 3 above).

S7 Skill 7: Identifying the critical points (points of highest stress) in a beam in $\quad \begin{array}{ll}2.5 & 3.9\end{array}$ bending, a circular bar in torsion, any bar under uniaxial load, and a bolt in single shear.

S8 Skill 8: Setting up a combined-loading stress state at a critical point, i.e., identifying and formulating the expressions for $\sigma_{x}, \sigma_{y}$, and $\tau_{x y}$ in the figure shown on the right, based on the forces and moments calculated with free-body diagrams.

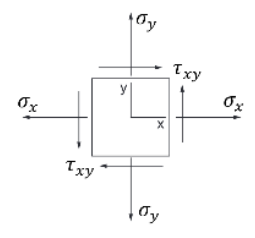

S9 Skill 9: Using an appropriate failure theory to size a machine component. 
Statistical significance was determined using Student's t-test which assumes that the data is normally distributed. The distribution of scores for Skill 4 and Skill 8 are shown in Fig. 7 to show that the shape of the graphs resembles a normal distribution curve. The shape of the graphs of the other seven skills were similar.

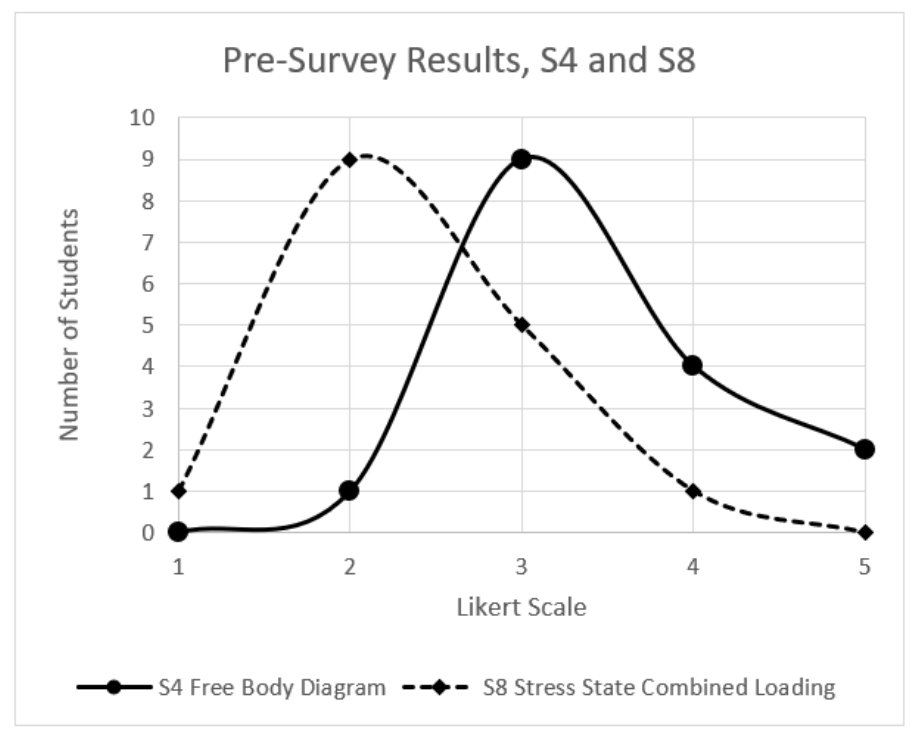

Fig. 7. Distribution of scores for Skill 4 (drawing free body diagrams) and Skill 8 (setting up the stress state due to combined loading). The shapes resemble a Gaussian probability density distribution (normal distribution), a requirement for Student's t-test. The shapes of the other seven skills were similar.

The author assembled the following student comments that were made during class discussions or during individual conversations.

- "I really enjoyed working with a real-world machine. Having the machine available for inspection really assisted me in understanding the knowledge learned in class and how to apply it to a real-world case". Some form of the benefits of using a "real-world" machine was the most frequent comment made by students.

- "I am glad that it was not a "final project" type exercise because I do not think that I would have been able to complete it in two or three weeks at the end of the semester. By conducting it in phases throughout the semester, I had the required time to understand each machine element and to complete the entire project".

- "I liked the feedback that I received when the professor graded each phase, as well as the feedback received during class discussions and office hours. It really helped in clearing up some concepts".

- "I think that it was very good that the project was synchronized with the class material. Studying for the exams served me directly and immediately in completing some of the phases in the project." 


\section{Discussion}

The results of the survey show that the project was very effective in achieving its objectives. All the skills improved, and all the improvements were statistically significant. Furthermore, the direct assessment of the projects, conducted by the author while grading, confirmed this finding.

The results of Skill 9 (sizing) were particularly meaningful because achieving mastery in sizing of machine elements was the principal objective that the author wanted to accomplish. It had the lowest average score (1.9) in the pre-survey, which was expected since they did not possess that knowledge, while it also achieved the highest average score (4.6) in the post-survey.

Skills S4 through S8 represented skills from the prerequisite courses of statics and mechanics of materials. The pre-survey detected weaknesses in all of them, particularly S7 (identifying critical points), with a score of 2.5, and S8 (combined loading stress state), with a score of 2.4. The statistically significant improvements in the post-survey results of these skills provide evidence of the merit of the scheme. The scores in the post-survey also correlate well with the judgment of the author while he directly assessed the quality of each project. The author believes that the use of the planning framework of "backwards design" [2] was crucial in achieving the objectives. The author planned the course so that the sequence of steps was the same for all the relevant machine components, i.e., draw a free body diagram (S4), draw a shear and bending moment diagram when appropriate (S5), calculate expressions for the stresses (S6), identify potential critical points (S7), determine the combined loading stress state (S8) at the critical points, and apply a failure criterion (S9). Furthermore, the author emphasized the maximum distortion energy failure criterion (von Mises) throughout the semester which created a level of repetition that he feels was valuable to infuse the knowledge required to master skills S4 through S9. The stresses were always determined as algebraic expressions which students manipulated to solve for the desired size dimension (diameter, for example). This methodology was conducted in class, homework, exams and in the project. On the areas that still require improvements, Skill 7 (identifying critical points) achieved the lowest score in the post-survey (3.9) which shows that it merits more emphasis in class discussions.

The improvements in S1 (figuring out the external loads) and S2 (finding out information on your own) were also very good. Many students had difficulties during Phase 1 which required them to determine the loads on the input shaft of the gearbox. $40 \%$ of the students performed poorly during Phase 1, particularly in learning on their own the force distribution on belt drives (slack and tight sides) that was required to determine the maximum overhung load due to the CVT. This required the author to conduct short lectures on belt drives and CVT's to clear up the issues. The students performed much better during Phase 2 which dealt with the tight and slack sides of chain drives. Still, the author conducted a feedback session to clear up the differences between belt drives (based on frictional forces) and chain drives which are positively driven by sprockets. Thereafter, students felt much more comfortable finding out information on their own, for example, from gear catalogues and ball bearing catalogues, when those phases took place, although some feedback was also provided during class and office hours to clear up any issues that arose. 
The final stages of the project required students to compare their results to the dimensions of the existing machine as a means to develop engineering judgment and expertise. Several "learning moments" arose during the comparison. The items have been divided by machine component.

\section{$\underline{\text { Gears }}$}

1. The conclusion was that the original gearbox was undersized. This was already a suspicion since the input shaft components failed during the competition. The diametral pitch (tooth size) of the original gearbox was $\mathrm{P}=12$ while the students calculated a minimum size of $\mathrm{P}=8$. Since lower values of $\mathrm{P}$ mean bigger teeth, it was determined that the existing gearbox used smaller teeth size than required. The gear material of the existing gearbox was low-carbon steel, without hardening. This same material was used for the sizing calculations.

2. The students inspected the gears of the existing gearbox and found that there was damage on the face of all the teeth at the location of the pitch circle. Fig. 8 is a photograph taken by one of the students. The tooth damage suggests that the gear teeth were overloaded during the competition. This observation points to the reasonableness of the students' sizing calculations that recommended a larger tooth size for the specified material.

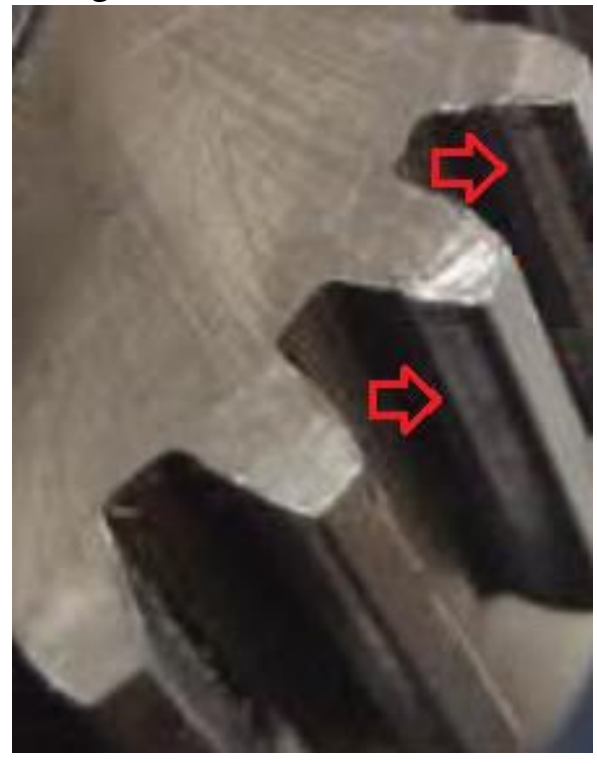

Fig. 8. Tooth damage on the gears of the existing gearbox.

3. While going through the gear capacity tables of the gear catalogue, it became clear to students that there was no way that the tooth size defined by $\mathrm{P}=12$ gear could withstand the torque and rpm delivered by the $10 \mathrm{hp}$ engine of the SAE Baja. This observation allowed them to start building "feeling" (engineering judgment) as to the relationship between engine horsepower and gear tooth size.

4. Even when considering a carburized hardened steel, the students were not able to show the adequacy of a $\mathrm{P}=12$ tooth size. An even stronger and surface-hardened material 
would be required to achieve a smaller tooth size. This issue was not further developed in the project due to time constraints.

5. The endurance limit of the gear material was independently calculated, and it was shown that it was 30\% higher than the values used in the catalogue. This led to a class discussion where it was speculated that the gear manufacturers had been "conservative" by reserving that extra $30 \%$ in strength as a margin of safety.

6. All the students selected and defended gear application factors (a form of safety factors) between 1.25 and 1.5 for the gear size calculation, which were appropriate for most applications. However, it was speculated that by virtue of being a competition where reduced weight is rewarded, the original gearbox designers may have opted to be more "aggressive" ("non-conservative") with the result that they may have used lower application factors (1.0 or 0.85 , as included in the catalogue) in their sizing calculations. A lower safety factor could be defended if the number of fatigue cycles could be limited to those in the competition and the practice time leading to the competition.

7. The students realized that their calculated larger gear sizes impacted negatively the weight of the gearbox. The size of the gearbox was approximately twice the size of the existing machine. They questioned if the larger gearbox would fit the SAE Baja, and the negative impact of the heavier gearbox. This line of questioning clearly showed that students were evaluating the constraints of the design. This is meaningful because the continuous evaluation of constraints is very typical in engineering practice [5]. The issue of optimizing the size was not developed further due to the time constraints.

8. The students also noted that the 2-inch sprocket on the output shaft of the existing gearbox was much lighter when compared to the gears that they had selected. This led to a class discussion in which it was realized that a chain drive with sprockets is much more efficient than a gear drive because the load of the chain is distributed among several teeth while a gear drive depends on just one tooth to transmit the load. This also became a "teachable moment" to address the concept of contact ratio because it is not actually one tooth transmitting the load but approximately 1.5 teeth, as the teeth rotate into and out of action. Still, the sprockets distribute the load among at least 5 teeth for the small 2-inch sprocket.

9. It was observed that the newer version of the Baja (Fig. 4) does not use a chain drive. Instead it uses a CVT and a commercial transmission that packs a 12:1 compound gear ratio, as well as a differential, that directly, and independently, drives the rear wheels of the Baja. Although it is twice the size of the gearbox used in this project, it efficiently packs a 12:1 gear ratio which makes it a very good selection. It also includes reverse. This issue was not developed further due to time constraints. This transmission is a very good candidate as a project for another group of students in a future course. 
$\underline{\text { Shafts }}$

1. The diameter of the low-carbon steel input shaft of the original gearbox was $d=0.5$ inch while the students calculated a minimum diameter of 1.25 inch, also for low-carbon steel AISI 1020. The fact that the original shaft failed, provided a measure of reasonableness to the larger calculated shaft size.

2. It was noted that the engine output shaft was 1.0-inch diameter. Assuming that the engine shaft is low-carbon steel, which is the material that was selected by students for the shafts, it would be reasonable to expect shafts of at least 1.0-inch diameter higher, as the gear ratios of the CVT, gearbox, and chain drives in the train augment the torque while reducing speed. This observation also pointed to the reasonableness of the calculated shaft sizes.

3. The shaft size calculations also provided an opportunity to analyse several failure modes, including bending fatigue, static shear due to torque, and deflection. The students then used the larger diameter as an input to calculate the critical speed of the shaft to show that it was approximately ten times higher than the maximum shaft speed. This was due to the short span of the shafts.

$\underline{\text { Bearings }}$

1. The ball bearings selected for the original gearbox had a bore diameter of 0.5 inch which would not satisfy the reactions calculated at the bearings. The students calculated a minimum bearing bore diameter of 1.0 inch.

2. The students had the opportunity to observe that the capacity of the ball bearing "series" given in a textbook table were the same ones used in the manufacturers' catalogues, in this case the Timken catalogue. They also observed that the manufacturer had several options to strengthen the ball bearings, thus deviating from the "series" capacity table in the textbook.

3. The students also had the opportunity to observe the differences in rated life of the bearings. The textbook table is based on a rated life of 90 million cycles while the rated life of the Timken catalogue bearings was only 1 million cycles. This required them to recalculate the capacity of the bearings, through the formulas in the textbook, to obtain the correct equivalence between the two tables.

\section{Conclusions}

This article has shown that mastery and expertise in sizing machine components can be achieved by using an existing machine as a sizing project in a machine design course. The learning experience is enriched using a tangible, real-world machine, and by the comparisons that take 
place, which develop engineering judgment. A calculated size, without checking its reasonableness, makes it difficult to develop "feeling" and engineering judgment. It was also shown that this scheme is grounded on the literature of achieving expertise. It was shown that this approach is solidly based on the literature of developing expertise, particularly "conditionalizing" knowledge by providing the context of a real machine.

The experience was further strengthened by utilizing the "backwards design" planning framework which ensured that the project had a proper fit within the course. The presentation of the course material was well synchronized with the exams and the project, and effective feedback was provided to students throughout the entire semester. All the situations that arose in class were used as "teaching moments" since the end result of the course was crystal clear to the instructor and the students. This scheme also eliminated additional project requirements that could dilute the effort.

Variety may be incorporated by selecting a different machine every semester. This avoids the temptation of students to copy from previous semesters. This also maintains the instructors' level of enthusiasm and motivation because of the exposure to new learning opportunities and the potential to continue building their own engineering judgement. The plan for next semester is to use a lathe from the machine shop. In this case, the lathe is a commercial machine that was designed by experts, unlike the Baja that was designed by students. The comparison of results will be of a slightly different nature and should match more closely with the existing components. Future editions of the project will also incorporate more guiding questions for the students to answer in their reports.

This article has also established the merit of shifting the emphasis to "expertise development" rather than attempting to measure "student learning" directly. Further research is contemplated along this line.

\section{References}

[1] Juvinall, R.C., and Marshek, K.M., Fundamentals of Machine Component Design, 5th edition, John Wiley and Sons, 2012.

[2] Wiggins, G.P., and McTighe, J., Understanding by Design, Alexandria, VA: Association for Supervision and Curriculum Development, 2005.

[3] ABET new outcome 7. URL: https://www.abet.org/accreditation/accreditationcriteria/criteria-for-accrediting-engineering-programs-2019-2020/\#4 Retrieved January 2, 2019.

[4] Bransford, J., Brown, A., \& Cocking, R. (Eds.), How people learn: Brain, mind, experience, and school (Expanded E). Washington, D.C.: National Academy of Sciences, 2000.

[5] Bornasal, F., Brown, S., Perova-Mello, N. and Beddoes, K., Conceptual Growth in Engineering Practice. Journal of Engineering Education, 107: 318-348, April 2018 doi: $10.1002 /$ jee. 20196 
[6] Litzinger, T., Lattuca, L. R., Hadgraft, R. and Newstetter, W. (2011), Engineering Education and the Development of Expertise. Journal of Engineering Education, 100: 123-150, January 2011. doi:10.1002/j.2168-9830.2011.tb00006.x

[7] Entwistle, N. J., \& Peterson, E.R., Conceptions of learning and knowledge in higher education: Relationships with study behavior and influences of learning environments. International Journal of Educational Research, 41(6), 407-428, 2004.

[8] Vermunt, J. D. (1996). Metacognitive, cognitive and affective aspects of learning styles and strategies: A phenomenographic analysis. Higher Education, 31(1), 25-50.

[9] Pierce, R. S., \& Stone, W. L., \& Kaul, S. (2017, June), Integration of Engineering Theory and Practice in a Junior-Level Machine Design Course Paper presented at 2017 ASEE Annual Conference \& Exposition, Columbus, Ohio. https://peer.asee.org/28567

[10] Youssef, G., \& Kabo, J. M. (2015, June), Machine Design: Redesigned Paper presented at 2015 ASEE Annual Conference \& Exposition, Seattle, Washington. 10.18260/p.24439

[11] Wood, J., Campbell, M., Wood, K., \& Jensen, D. (2005). Enhancing the Teaching of Machine Design by Creating a Basic Hands-On Environment with Mechanical 'breadboards.' International Journal of Mechanical Engineering Education, 33(1), 1-25. https://doi.org/10.7227/IJMEE.33.1.1

[12] Wood, J. J., Jensen, D. D., \& Wood, K. (2005). Enhancing Machine Design Courses Through Use of a Multimedia-Based Review of Mechanics of Materials. In Proceedings of the ASEE Annual Conference.

[13] Farouki, R. T., \& Linke, B. S. (2016). Shigley Hauler - A competitive project illustrating basic machine design principles. International Journal of Mechanical Engineering Education, 44(4), 284-301. https://doi.org/10.1177/0306419016669189

[14] Farouki, R.T. URL: https://faculty.engineering.ucdavis.edu/farouki/wpcontent/uploads/sites/41/2014/06/project.pdf Retrieved January 2, 2019.

[15] Yilmaz, E., Wheel Balancing Machine Design Paper presented at 2000 Annual Conference, St. Louis, Missouri. https://peer.asee.org/8848 